\title{
Interaction in spoken academic discourse in an EMI context: the use of questions
}

\section{Jane Helen Johnson, Mariangela Picciuolo}

Department of Modern Languages, Literatures and Cultures, University of Bologna, Italy.

\begin{abstract}
Studies on metadiscourse (Hyland 2005) have focussed on engagement as interaction. An example of engagement is asking questions (Hyland 2009: 112) and indeed the importance of questioning for content learning has been researched extensively in pedagogical studies as fundamental in coconstructing meaning (Dafouz Milne \& Sanchez Garcia 2013: 130). Research in an English Mediated Instruction (EMI) context found that teachers' usage of questions in the classroom was affected by low levels of language competence and in these cases, strategies such as questioning could easily be underused or even misused, thus affecting the teaching and learning of content (Drljaca Margic \& Vodopija-Krstanovic 2018: 32).

Our study examines lecturer questioning at an Italian University by triangulating face-to-face surveys of lecturers, student questionnaires, and transcribed lecture recordings. Findings have practical applications for providing targeted coaching for non-native EMI lecturers with regard to appropriate linguistic strategies to encourage interaction, and also have implications for research into linguistic strategies used within EMI.
\end{abstract}

Keywords: Questioning, Spoken Academic Discourse, EMI. 


\section{Introduction}

Establishing interaction plays a fundamental role in social communication (Hyland 2005; Molino 2018). Studies on metadiscourse in English for Academic Purposes (EAP) in both spoken and written texts have focused on interaction through engagement. One example of engagement in the classroom is asking and answering questions (Hyland 2009), and such patterns of interaction are a powerful resource in scaffolding students' learning (Coffin 2010; Morell 2004). The importance of questioning for content learning has been researched extensively in pedagogical studies as one of the main ways meaning is co-constructed (Dafouz Milne \& Sanchez Garcia 2013: 130).

EAP research into questioning has also focussed on lecture discourse (Crawford Camiciottoli 2008; Chang 2011; Dafouz Milne \& Sanchez García 2013; Morell 2004). A number of studies have adopted a discourse-analytical perspective to focus on audience-oriented discourse markers versus content-oriented discourse markers. Crawford Camiciottoli (2008) refines these divisions into sub-functions, describing content-oriented discourse markers as either focusing information and/or stimulating thoughts, while audience-oriented markers are used for eliciting response, soliciting agreement or requesting clarification. Audienceoriented markers thus all aim to stimulate some sort of interaction.

Our study focuses on the spoken English of Italian lecturers teaching in English as the Medium of Instruction (EMI) across two macro-disciplines: Physical Sciences (PS) and Social Sciences (SS). In Italy lecturers are not required to have any teaching qualification, nor are obliged to undertake any training in order to perform their teaching activities, even in their first language. Costa and Coleman (2013) found that teaching styles in most Italian universities were based on traditional, monologic lectures: a format generally incompatible with stimulating questioning (Northcott 2001). In addition, many Italian lecturers have weak English language competence (Campagna \& Pulcini 2014). It has been suggested that weak English in an EMI context affects teachers' use of questions (Dafouz Milne \& Sanchez Garcia 2013), possibly leading to underuse or misuse of certain classroom discourse strategies (Molino 2015), and thus negatively affecting both the teaching and learning of content (e.g. Drljaca Margic \& Vodopija-Krstanovic 2018: 32).

In order to collect data to identify issues and attitudes towards EMI so that teaching support could be provided, we interviewed lecturers teaching on Bologna University's international degree courses. The students attending these courses were also asked to complete an online questionnaire. Our aim was to find out 1) whether questions are used in EMI lectures, and if so, 2) what sort of questions, as well as what 3) lecturers and students say about the use of questions in their lectures. We also wanted to know whether findings varied according to the macro-disciplinary area. 
Below we compare the frequency and function of questioning across SS and PS lectures and compare this with both lecturers' and students' perceptions. In this way our aim is also to triangulate findings between what lecturers and students say takes place in the lecture, and the lecture itself. Our hypothesis was that, given the lecturers' general lack of training and weak English language competence, there would be little room for questioning. We also expected to find issues impeding the correct use of questions, such as non-standard pronunciation, intonation and syntax. Considering the predominant monologic lecture style in Italy, we would also expect questions to be content-oriented rather than audience-oriented.

\section{Methodology}

\subsection{Lecturer survey}

18 PS and 22 SS lecturers from Masters' degree courses were interviewed. Participants were asked, in Italian, what interactive teaching techniques they used. Typical questions were:

- How satisfied are you with the level of interaction in your EMI lecture?

- Do you do anything to promote interaction in the classroom? If so, what?

Lecturers were also asked about their teaching experience and training, their teaching style and classroom practice, and the number of non-Italian students attending their classes.

\subsection{Student questionnaire}

Students were asked to complete an anonymous online questionnaire. 23 students participated. Questions included:

- How satisfied are you with the level of interaction in EMI lectures?

- Does the lecturer usually ask questions?

- Is it easier for you to learn if the teacher asks questions? 


\subsection{Lecture recordings}

Data concerning the lecture recordings is shown in Table 1. After transcription, questions were identified and divided into audience- or content-oriented.

Table 1. Details of lecture recordings.

\begin{tabular}{lcccc}
\hline & Lectures & Lecturers & Time & Words \\
\hline Physical Sciences & 8 & 7 & 9 hours & 52784 \\
Social Sciences & 3 & 3 & 7 hours & 22567 \\
\end{tabular}

\section{Findings}

\subsection{Lecturer surveys}

The average class size for both SS and PS lecturers was 25-50 students. Such numbers would be ideal for the use of interactive strategies (Crawford Camiciottoli, 2007; Lee \& Subtirelu, 2015).

Over $50 \%$ of the students in most PS classes were non-Italians, while over half of the SS classes surveyed had up to $50 \%$ or fewer internationals.

The majority (75\%) of lecturers had followed no course in teaching in English, but had had more than five years' experience teaching in English.

Nearly all lecturers claim to make use of the monologic lecture style, though just over $50 \%$ also use the workshop/seminar style. In the case of the monologic lecture, we thus assume that little face-to-face interaction would take place in class, although $70 \%$ of lecturers also claim to set up group and/or pairwork activities at some time during the lecture. Peer teaching in the form of short class presentations was also mentioned. SS lecturers also mention the discussion of case studies as collaborative exercises.

\subsection{Student questionnaires}

Both students and lecturers share the same perceptions about classroom interaction, as regards teaching style, with most students confirming that the traditional teacher-fronted style predominated. However, while lecturers referred to questioning as their main technique to encourage interaction, asking questions to elicit response from their students, the students mentioned other classroom activities such as collaborative group discussion. A few also noted comprehension check questions (Ok? Does everybody understand?) as an interactive technique. 
Students confirmed that lecturers asked questions in class. Some PS students showed they were aware of the rationale behind this, mentioning that lecturers' questioning encourages students' conceptual understanding. Most students said they answered lecturers' questions, and even asked questions themselves.

\subsection{The transcripts}

Over $80 \%$ of PS lecturers' 'questions' were found to be progression markers such as $o k$, right? and no?, while in SS lectures, progression markers made up just $25 \%$ of all 'questions'. Crawford Camiciottoli (2008) disregards progression markers considering them not real questions, since "lecturers do not really engage with students or wait for their reaction" (2008: 1221). We also discounted progression markers as questions since they do not stimulate interaction. SS lecturers asked more questions (5.8 per 1000 words) than PS lecturers (3.5 per 1000 words). However, there was also much variation among the individual lecturers. One PS lecturer used 8 questions per 1000 words, for example, while at the other end of the scale, two PS lecturers asked $<1$ question per 1000 words. Instead, the SS lecturer who most frequently asked questions used 15 per 1000 words, while the other two SS lecturers asked $<3$ questions per 1000 words.

If we consider individual lecturers' contributions, the highest question frequency was in SS, while the lowest frequencies were in PS. However, four PS lecturers used questions with greater frequency than the remaining two SS lecturers. These findings suggest that any interpretation of the results pertaining to question frequency and discipline should be done carefully. Table 2 shows the breakdown of the total questions considered, and the division into audience- or content-oriented.

Table 2. Questions in lecture transcripts.

\begin{tabular}{lcc}
\hline & SS & PS \\
\hline Questions (minus prog. markers) & 109 & 128 \\
Questions /1000 words & 5.8 & 3.5 \\
Audience-oriented & $101(93 \%)$ & $84(66 \%)$ \\
Content-oriented & $8(7 \%)$ & $44(33 \%)$ \\
\hline
\end{tabular}

Audience-oriented markers - actual questions that the students might answer - were found to make up $93 \%$ of SS lecturer questions compared to $66 \%$ in PS lectures. Content-oriented questions to make the audience focus, mainly followed immediately by the lecturer's answer, were much more typical of PS lectures (33\% of questions). 
A higher proportion of content-oriented questions would better help students to focus individually on the dense material which is the subject of the lecture, but this would be to the detriment of the level of interaction in the classroom.

\section{Discussion}

\subsection{Questioning in the two disciplines}

While Chang (2011) noted that questions for classroom management, such as audienceoriented questions, tend to be more frequent in SS classes, due to their more "persuasive and dialogic nature", in our study lecturers from both disciplines actually asked this type of question. However, there is much variation among lecturers of both disciplines, thus suggesting that individual attitudes and experience may contrast the 'nature' or culture of disciplinary knowledge.

\subsection{Perception of degree of interaction}

Both lecturers and students are aware of the current degree of interaction in their classroom and some of the strategies used to encourage it. However, for some lecturers, the lecture setting is mainly conceived as a transfer of knowledge, less dialogic and more controlling, and therefore interaction becomes unnecessary.

Although only $30 \%$ of PS and SS lecturers reported interaction in their classroom to be 'high' or 'very high', most were satisfied with the current level of interaction. They perceived three main constraints to promoting a higher level of interaction: 1) time constraints: more time dedicated to interaction would prevent them completing the course syllabus; 2) class size: the higher the number of students, the more difficult it is to engage them actively; and 3) cultural differences between international and Italian students.

Unlike their PS colleagues, SS lecturers also mentioned strategies other than questioning as their main interactive strategies, such as collaborative case studies and group discussions. Additionally, SS lecturers mentioned the active role played by international students, which led lecturers to adapt their teaching style appropriately.

\subsection{Influence of English language competence}

Lecturers also reported a lack of confidence in their own pronunciation and speaking ability in general. Indeed, as Molino (2015) also found, progression markers such as ok? mm eh? occurred 4 times more frequently in Italian EMI lecturers' speech than in native speakers' lectures. This could be due to lack of confidence in their own language competence during the elaboration of complicated content material, together with a greater perceived need to make sure the students understand. This might suggest the massive use of audience-oriented 
questions is not so much to promote interaction per se but just as a request for clarification. The use of more content-oriented questions among PS lecturers could be due to the type of material being taught, information-heavy and with little room for discussion. However, such lecturers also need to be able to actively stimulate student interaction, particularly in order to cater for international students and foster learning.

\subsection{Framing the questions}

Questions need to be asked effectively. Typical strategies of Italian speakers include using intonation and gestures to indicate questions, as well as adopting Italian syntax. These strategies could lead to misunderstanding. However, the transcripts also contained examples of good practice, such as the use of metalanguage to signal intentions: 'I'm going to ask you a question'.

\subsection{Students' experience with questions}

While all students claimed they answered lecturers' questions and even asked questions themselves, most students, particularly from PS, admitted they preferred asking questions at the end of the class. This represents a missed opportunity for other students to benefit from hearing the answers. As the transcripts showed, there were fewer audience-oriented questions in PS lectures, and thus PS students were given fewer opportunities to intervene by the lecturer. Only the more confident students therefore would venture to interrupt the lecturer.

\section{Conclusion}

Our original hypothesis was that, given the general lack of teacher training, weak English language competence, and prevalence of monologic lecture style in Italy in general, there would be little room for questioning. Instead, all lecturers mentioned their use of questioning to promote interaction in their classes. The transcripts however showed a discrepancy between their perceptions and what actually happened.

SS lecturers tended to adapt their teaching practices in favour of a more interactive classroom environment, also depending on the presence of international students. Instead PS lecturers mentioned cultural issues which prevented them from achieving a higher level of engagement in their classes.

We found some adaptation of the teaching style in general, with an increase in audienceoriented questions, though there was a much higher proportion of content-oriented questions in PS lectures than in SS lectures.

The presence of non-standard question formulation and the reliance on 'questioning intonation' was evident, though signalling metadiscourse was occasionally found in the transcripts. 
Our lecturer sample however was small and further research is required to seek out less experienced lecturers and add to the corpus of lecture transcripts.

Adequate training is essential in order to raise awareness in lecturers about how their language choices ultimately encourage or discourage interaction and thus learning (Costa 2016). A fine example illustrating this is the common lecture-final "Any questions? No questions", which on no occasion produced any response.

Pedagogical training has been described as more necessary than language training (Klaassen 2001). In addition, the acquisition of interpersonal competence in communicative multicultural settings in English is fundamental.

Practical applications for providing targeted coaching for non-native speaker EMI lecturers with regard to appropriate linguistic strategies could include peer reviewing and commentary on other lectures, with particular focus on questioning; raising awareness as to which questions are answered by students, with subsequent discussion as to why this might be; inviting lecturers to review their own recordings and commenting on and improving their own use of questions, to promote interaction; as well as exercises involving rephrasing questions.

EAP teachers need to better understand the discourse preferences of university instructors and the interactive features used in content courses (Lee \& Subtirelu 2015: 61) and likewise "university faculty may also benefit from understanding the ways in which experienced EAP instructors seek to make academic discourse accessible" (ibid.). While their conclusions refer to metadiscourse in general, this certainly applies to strategic and appropriate use of questioning in the classroom.

\section{References}

Campagna, S., \& Pulcini, V. (2014). English as a Medium of Instruction in Italian Universities: Linguistic policies, pedagogical implications. Textus. English Studies in Italy. Perspectives on English as a Lingua Franca, 27(1), 173-190.

Chang, Y. (2011). The use of questions by professors in lectures given in English: Influences of disciplinary cultures. English for Specific Purposes, 31(2), 103-116.

Coffin, C. (2010). Language support in EAL contexts. Why systemic functional linguistics? (Special Issue of NALDIC Quarterly). Reading, UK: NALDIC.

Costa, F. (2016). CLIL (Content and Language Integrated Learning) through English in Italian higher education. Milan, Italy: LED, Edizioni Universitarie di Lettere Economia Diritto.

Costa, F., \& Coleman, J. (2013). A Survey of English-Medium Instruction in Italian Higher Education. International Journal of Bilingual Education and Bilingualism, 15(4), 1-17.

Crawford Camiciottoli, B. (2007). The Language of Business Studies Lectures. A CorpusAssisted Analysis. Amsterdam/Philadelphia: John Benjamins Publishing Company. 
Crawford Camiciottoli, B. (2008). Interaction in academic lectures vs. written text materials: The case of questions. Journal of Pragmatics, 40 (7), 1216-1231.

Dafouz Milne, E., \& Sanchez García, M. D. (2013). Does everybody understand?' Teacher questions across disciplines in English-mediated university lectures: An exploratory study. Language Value, 5(1), 129-151.

Drljaca Margic, B., \& Vodopija-Krstanovic, I. (2018). Language development for Englishmedium instruction: Teachers' perceptions, reflections and learning. Journal of English for Academic Purposes, 35, 31-41.

Hyland, K. (2005). Metadiscourse: exploring interaction in writing. London, England: Bloomsbury.

Hyland, K. (2009). Corpus Informed Discourse Analysis: The Case of Academic Engagement. In M. Charles, D. Pecorari, \& S. Hunston (Eds.), Academic Writing: At the Interface of Corpus and Discourse (pp. 110-128). London, England: Bloomsbury.

Klaassen, R. (2001). The International University Curriculum. Challenges in EnglishMedium Engineering Education (Doctoral dissertation). Delft, Netherlands: Technisch Universiteit Delft.

Lee, J. J., \& Subtirelu, N. (2015). Metadiscourse in the classroom: A comparative analysis of EAP lessons and university lectures. English for Specific Purposes, 37, 52-62.

Molino A. (2015). Comprensione e interazione nelle lezioni universitarie in lingua inglese, Ricognizioni. Rivista di lingue, letterature e culture moderne, 4(2), 129-143.

Molino A. (2018). What I'm Speaking is almost English... A Corpus-based Study of Metadiscourse in English-medium Lectures at an Italian University. Educational sciences: theory \& practice, 18(4), 935-956.

Morell, T. (2004). Interactive lecture discourse for university ELF students. English for Specific Purposes, 23(3), 325-338.

Northcott, J. (2001). Towards an ethnography of the MBA classroom: a consideration of the role of interactive lecturing styles within the context of one MBA programme. English for Specific Purposes, 20(1), 15-37. 